\title{
Evaluation of high temperature ceramic sensor packages
}

\author{
Paul Gierth, Lars Rebenklau, Henry Barth \\ Fraunhofer IKTS, Winterbergstrasse 28, 01277 Dresden, Germany \\ paul.gierth@ikts.fraunhofer.de
}

\begin{abstract}
Summary:
Modern sensor elements could in many cases withstand very high environmental temperatures. Their only limitations are caused by packaging concepts. Therefore, novel-ceramic packaging concepts seem a promising platform for reaching the next application level. This work discusses technologies, materials and evaluation methods for reaching high temperature stable package solutions. Especially materials for sensor chips mounting inside ceramic packages and package connector mounting up to $600{ }^{\circ} \mathrm{C}$ were focused and discussed.
\end{abstract}

Keywords: high temperature, packaging, ceramic, interconnection, brazing

\section{Motivation}

Every kind of industrial process can only be performed if enough sensor signals could be used to control this process. Therefore, many sensors need to withstand very harsh environments, like high pressures, acid atmospheres or simply high temperatures.

Existing packaging technologies are based on integrating a sensor element in a metallic or ceramic package and hermetically sealing it. All therefore needed process steps needs to be further developed to fulfill requirements of higher environmental temperatures. The complete sensor packaging process can be splitted into five separate steps according Fig. 1.

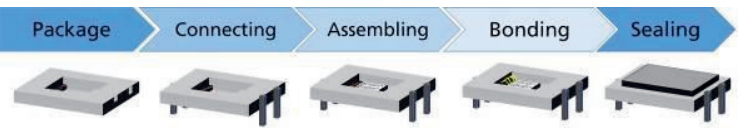

Fig. 1. Process flow of sensor element packaging.

Packaging process is divided into package material selection (step 1), package connection if needed (step 2), assembling of the sensor element inside the package (step 3), interconnection between package and sensor element (step 4) and hermetical package enclosing (step 5). Influence of high temperatures on packages and their electrical characteristics is already discussed in [1]. Long time stability of welded interconnection joints at high temperatures was evaluated in [2] and first connecting and assembling results were shown in [3].

Present study is further focusing on assembling and sealing technologies. Main aim of this work is to discuss active brazing as high temperature sealing technology.

\section{Characterization of assembling joints up to $600{ }^{\circ} \mathrm{C}$}

Active brazing joints, sintering materials, or ceramic adhesives could be used to realize high temperature stable sensor assembling inside a ceramic package. Ceramic adhesives show nearly identical thermal expansion to the ceramic package itself whereby they should be preferred. Mechanical stability of these kind of joints could only be inspected before and after a high temperature storage, but not under real conditions. Therefore, a high temperature shear-strength measurement setup has been developed (Fig. 2).

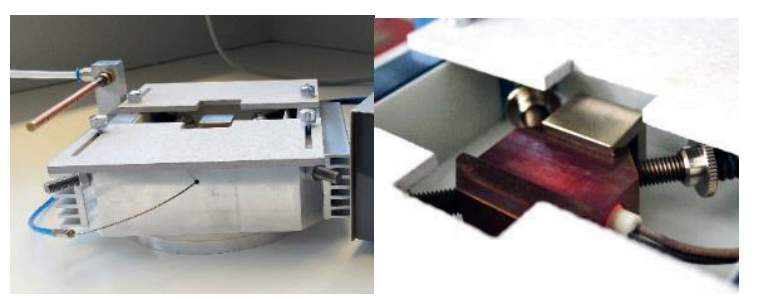

Fig. 2. High temperature shear test rig. left: complete rig with cooling airflow and temperature control, right: core heating table heated up to $600{ }^{\circ} \mathrm{C}$.

The developed test rig was mounted on a Dage Series 4000 shear-force measurement tool and different high temperature adhesives were evaluated. It could be found that all kind of ceramic adhesives show completely different mechanical joint characteristics und different test temperatures (Fig. 3). Even promising materials, which should withstand temperatures up to over $900{ }^{\circ} \mathrm{C}$, could show enormous interface degradations und real conditions (Fig. $3 \mathrm{SiO}_{2}$ ). 


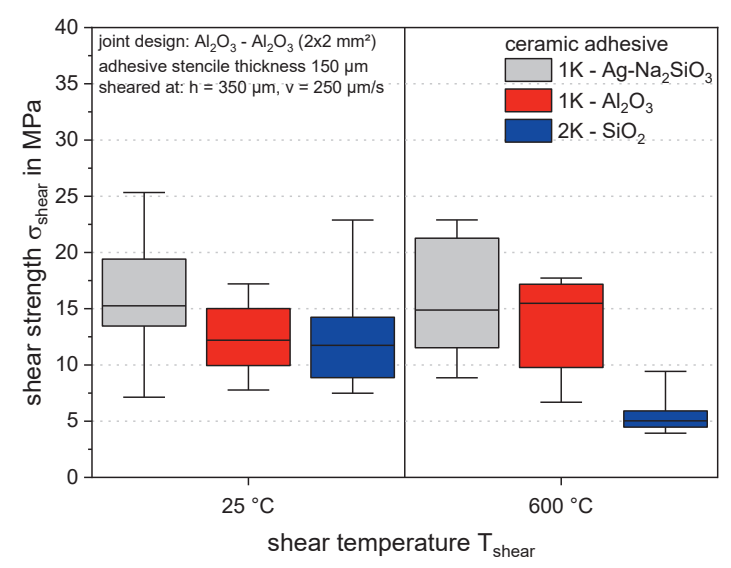

Fig. 3. Comparison of assembling adhesive joint strength at different test temperatures

\section{High temperature packaging sealing}

Sealing of packages can be performed in different ways. Metal-cap packages often use welding technologies for sealing. Soldering could also be a suitable solution but is only possible if solderable metallic surfaces are applied on the package and the sealing element. An alternative high temperature stable sealing strategy could be the use of active brazing materials. These materials can be used to interconnect ceramics directly. The fundamental working principle is based on generating a solderable surface on the ceramic during the brazing process by adding an active element into the material. For example, silver-copper-titanium compositions are often used as active brazing material. Silver and copper itself are not able to attach to a ceramic substrate. But titanium is interacting with the ceramic itself and generating a solderable surface layer during the brazingprocess. Eutectic AgCuTi brazing paste is applied directly on the ceramic surface of the package. The ceramic lid is placed into the paste and fixed by using a graphite mounting element. After an optimized drying process, a vacuum brazing step toke place between 850 $925^{\circ} \mathrm{C}$ to optimize the joint adhesion.

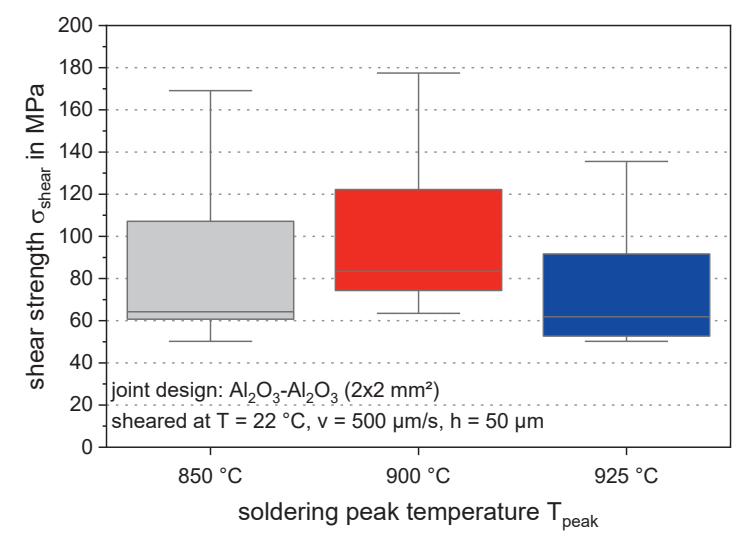

Fig. 4. Comparison of active brazing joint strength at different brazing temperatures
Fig. 4 shows very high joint strengths under all evaluated conditions, which indicates excellent adhesion between brazing material and ceramic. Most fracture modes were ceramic breakage. Cross sections were prepared to further investigate the joining quality (Fig. 5).

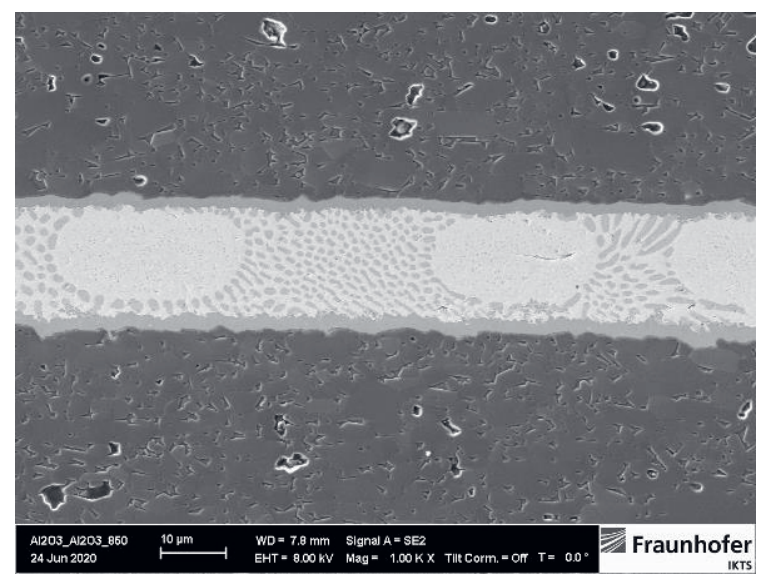

Fig. 5. Cross section of a ceramic-ceramic hermetic sealing using a AgCuTi active brazing material

As can be seen, a hermetical sealing between the ceramic elements could be realized with active brazing material. The very thin titanium layer and the ceramic surface is nearly not visible but the brazed copper film on this titanium layer can clearly be seen. The complete joining area consisting of a mixture between silver and copper, which shows a different morphology in dependency of the joining temperature.

As last thermal process during the production of high temperature stable packages, all previously applied technologies needs to withstand the joining temperature of the sealing. To prevent an overheating of the components, an alternative sealing brazing material could also be chosen, which are available in many different compositions starting from nearly $600{ }^{\circ} \mathrm{C}$ up to 1000 ${ }^{\circ} \mathrm{C}$

\section{References}

[1] L. Rebenklau, P. Gierth, H. Barth, HighTemperature Packaging for Sensors, PCIM Europe 2019, 1-7 (2019); ISBN: 978-3-80074938-6

[2] P. Gierth, L. Rebenklau, Development and analysis of high temperature stable interconnections on thick films using micro resistance welding for sensors and MEMS, 7th Electronic SystemIntegration Technology Conference (ESTC), 1-5 (2018), doi: 10.1109/ESTC.2018.8546509.

[3] P. Gierth, L. Rebenklau, H. Barth, Validation of High-Temperature Stable Sensor Packaging Materials and Methods, SMSI 2020, 244-245 (2020), doi: 10.5162/SMSI2020/P2.10 